\title{
ANALISIS SISTEM PEMASARAN CENGKEH (SYZYGIUM AROMATICUM) DI KECAMATAN LHOKNGA KABUPATEN ACEH BESAR
}

\author{
(Analysis Of Clove (Syzygium aromaticum) Marketing System In Lhoknga \\ Subdistrict, Aceh Besar Regency)
}

\author{
Arie Naufal ${ }^{1}$, Azhar $^{1}$, Agus Nugroho ${ }^{1 *}$ \\ ${ }^{1}$ Program Studi Agribisnis, Fakultas Pertanian, Universitas Syiah Kuala
}

\begin{abstract}
Abstrak Cengkeh saat ini menjadi komoditi andalan daerah Provinsi Aceh selain pala, lada, nilam dan tebu. Beberapa daerah yang menjadi sentral, salah satunya adalah Kecamatan Lhoknga. Banyak permasalahan yang dihadapi oleh para petani diantaranya harga yang fluktuatif serta daya tawar yang rendah. Peran lembaga-lembaga pemasaran juga menetukan efektivitas suatu sistem pemasaran. Penelitian ini bertujuan untuk melihat fungsi pemasaran cengkeh didaerah penelitian, selain itu juga untuk melihat marjin pemasaran dan pola pemasaran yang paling menguntungkan bagi petani cengkeh di Kecamatan Lhoknga. Penelitian ini dilakukan dengan analisis deskriptif kuantitatif kualitatif. Teknik pengambilan sampel petani menggunakan purposive sampling dan untuk lembaga pemasaran menggunakan snowball sampling. Hasil penelitian menunjukan bahwa fungsi pemasaran yang dilakukan oleh petani meliputi fungsi pertukaran berupa kegiatan penjualan. fungsi fisik berupa pengolahan (penjemuran), penyimpanan dan pengangkutan. Fungsi fasilitas berupa perolehan informasi pasar. Fungsi pemasaran yang dilakukan oleh lembaga pemasaran relatif sama yaitu fungsi pertukaran berupa pembelian dan penjualan. Fungsi fisik berupa penyortiran, penjemuran, penyimpanan, dan pengangkutan. Fungsi fasilitas yaitu jaminan harga dengan perjanjian tertentu, dan informasi pasar. Marjin pemasaran dan nilai farmer share pada saluran pemasaran I yang melibatkan petani, pedagang pengumpul desa, pedagang pengumpul kota, dan konsumen (supplier) memiliki marjin total pemasaran sebesar Rp. 7000 per kg dengan nilai farmer share $92,63 \%$. Pada saluran II yang melibatkan petani, pedagang pengumpul kecamatan, dan konsumen (supplier) menghasilkan marjin total sebesar Rp. 5000 per kg dengan nilai farmer share $94,73 \%$. pada saluran III yang melibatkan petani, pedagang pengumpul kota, dan konsumen (supplier) menghasilkan marjin total sebesar Rp. 3000 per kg dengan nilai farmer share 96,84\%.

Kata kunci: sistem pemasaran, efisiensi pemasaran, cengkeh, kecamatan lhoknga

Abstract Nowaday, clove is the mainstay commodity of Aceh Province besides to nutmeg, pepper, patchouli and sugarcane. Some regions that are central of cloves, one of that regions is Lhoknga District. Many problems faced by farmers include fluctuating price and low bargaining power. The role of marketing institutions also determines the effectiveness of a marketing system. This research aims to look at the marketing function of clove in the research area, in addition to seeing the marketing margin and the most profitable marketing pattern for clove farmers in Lhoknga District. This research was conducted with qualitative and quantitative descriptive analysis. The sampling technique of farmers using purposive sampling, and for marketing institution using snowball sampling. The result of research is showing that the marketing function carried out by farmers includes the exchange function in the form of sales activities, physical function in the form of processing (drying), storage and transportation. Facility function in the form of obtaining market information. The marketing function carried out by marketing institutions is relatively same, the exchange function in the form of buying and selling. The physical function in the form of sorting, drying, storage and transportation. Facility function are price guarantee with certain agreement, and market information. Marketing margin and farmer share value on marketing channel I involving farmers, village collectors, city collectors, and consumers (suppliers) having a total marketing margin of Rp. 7000/kg with $92.63 \%$ farmer share value. In channel II which involving farmers, subdistrict collectors, and consumers (suppliers) producing a total margin of Rp. 5000/kg with $94.73 \%$ farmer share value. In channel III involving farmers, city collectors, and consumers (suppliers) generating a total margin of Rp. 3000/kg with $96.84 \%$ farmer share value.
\end{abstract}

Keywords: marketing system, marketing efficiency, cloves, lhoknga subdistrict 


\section{PENDAHULUAN}

Indonesia merupakan negara yang memiliki potensi sumber daya alam yang besar. salah satu subsektor pertanian yang sagat penting adalah subsektor perkebunan dimana kontribusinya pada tahun 2017 sebesar 471,31 trilliun rupiah terhadap PDB (Ditjenbun dalam sawitindonesia.com, 2018). Salah satu tanaman perkebunan yang terkenal di Indonesia adalah cengkeh. Cengkeh (Syzygium aromaticum) merupakan tanaman asli Indonesia dari keluarga pohon Myrtaceae. Cengkeh digunakan sebagai bahan bumbu masak dan bahan utama rokok kretek. Cengkeh merupakan komoditi perkebunan yang memiliki nilai ekonomis yang tinggi. Seiring dengan perkembangan industri rokok di Indonesia, cengkeh memiliki peluang pasar yang menjanjikan.

Berdasarkan data Ditjenbun (2015), provinsi dengan luas tanam cengkeh terbesar adalah Sulawesi Utara dengan luas areal tanam 74.825 hektare. Sedangkan untuk wilayah pulau Sumatera provinsi Aceh tercatat sebagai wilayah terbesar produksi cengkeh dengan total produksi 4.577 ton dan luas areal tanam 22.476 hektare. Salah satu kawasan produksi cengkeh di Aceh adalah Kecamatan Lhoknga Kabupaten Aceh Besar. Dari tahun ke tahun luas lahan cengkeh terus mengalami peningkatan. Dari hasil pra-survei petani juga menyebutkan bahwa tanaman cengkeh mulai giat dikembangkan kembali sejak tahun 2014.

Dengan adanya peningkatan jumlah produksi setiap tahunnya mengindikasikan bahwa cengkeh sangat membantu perokonomian masyarakat, tentunya dengan harapan harga yang tinggi serta stabil. Namun pada kenyataannya petani mengaku bahwa harga cengkeh cenderung fluktuatif dan intensitas perubahan harga sangat sering. Perubahan harga yang terlalu sering tanpa adanya faktor yang jelas mengindikasikan bahwa adanya kegiatan pasar yang tidak semestinya. Dalam mekanisme memperoleh keuntungan, lembaga-lembaga pemasaran akan cenderung menekan harga ditingkat produsen atau di tingkat konsumen. Tetapi penekanan harga ditingkat konsumen akan sulit dilakukan karena sebagian besar konsumen cengkeh adalah perusahaan rokok kretek. Selain itu keuntungan petani juga dipengaruhi oleh biaya produksi dan lembaga-lembaga pemasaran yang terlibat didalamnya. Keberadaan kelembagaan desa seperti Koperasi Unit Desa (KUD) juga mempengaruhi pendapatan petani yang seharusnya KUD dapat membeli dengan harga yang lebih tinggi. Fungsi pemasaran yang tepat khususnya dalam hal peningkatan nilai produk juga akan memperkuat daya tawar petani mengingat harga cengkeh yang tidak stabil. Adapun tujuan dalam penelitian ini adalah untuk mengetahui fungsi pemasaran cengkeh, sebaran marjin pemasaran disetiap lembaga pemasaran, dan pola pemasaran yang paling menguntungkan bagi petani. Selain itu penelitian ini penting dilakukan karena kecamatan Lhoknga merupakan salah satu kawasan terbesar penghasil cengkeh di Aceh dan sebahagian besar petani memperoleh penghasilan dari cengkeh setelah dari hasil padi sawah.

\section{METODE PENELITIAN}

Penelitian ini dilakukan di Kabupaten Aceh Besar tepatnya di Kecamatan Lhoknga. Penelitian ini dilaksanakan di dua desa yaitu Desa Meunasah Lambaro dan Desa Meunasah Bale dengan pertimbangan bahwa desa tersebut adalah desa dengan areal tanam cengkeh terluas dan jumlah petani terbanyak di Kecamatan Lhoknga. Objek penelitian ini adalah para petani cengkeh yang ada di Kecamatan

Analisis Sistem Pemasaran Cengkeh (Syzygium Aromaticum) Di Kecamatan Lhoknga 
Lhoknga serta para pedagang yang terlibat dalam kegiatan pemasaran cengkeh dengan cakupan penelitian sebatas pada analisis sistem pemasaran cengkeh.

Penelitian ini dilakukan dengan analisis deskriptif kuantitatif kualitatif. Populasi dalam penelitian ini adalah masyarakat yang berprofesi sebagai petani cengkeh di Kecamatan Lhoknga dengan jumlah populasi pada dua desa yang dipilih sebanyak 46 petani dimana memiliki karakteristik yang homogen. Menurut Sumanto (1990) dalam Wirartha (2005) jumlah sampel minimal dalam penelitian deskriptif adalah $10 \%$ dari jumlah populasi. Jumlah sampel dalam penelitian ini sebanyak 15 petani dengan pembagian secara proporsional pada kedua desa. Teknik pengambilan sampel yaitu dengan purposive sampling dimana sampel ditentukan berdasarkan tujuan lembaga pemasaran cengkeh. Untuk lembaga pemasaran penentuan sampel dilakukan dengan teknik snowball sampling dengan jumlah responden disesuaikan di lapangan.

\section{Metode Analisis}

\section{a. Analisis Saluran Pemasaran}

Analisis saluran pemasaran digunakan untuk mengetahui saluran pemasaran yang dilalui dalam pemasaran cengkeh dari petani sampai ke konsumen. Dari analisis saluran pemasaran ini dapat diketahui berapa banyak jumlah lembaga pemasaran yang terlibat dalam pemasaran cengkeh di kecamana Lhoknga. Selain itu juga dapat diketahui pola saluran pemasaran yang terjadi berdasarkan lembaga pemasaran yang terlibat dalam pemasaran cengkeh tersebut.

\section{b. Analisis Fungsi Pemasaran}

Analisis fungsi pemasaran ini dilakukan untuk mengetahui fungsi-fungsi yang dilakukan oleh masing-masing lembaga pemasaran termasuk produsen dalam hal ini petani cengkeh. Analisis fungsi pemasaran ini dilakukan untuk mengetahui kegiatan pemasaran yang dilakukan oleh lembaga pemasaran dalam proses pemasaran cengkeh dari petani sampai ke konsumen. Fungsi pemasaran menurut limbong (1987) meliputi 1) fungsi pertukaran yang meliputi pembelian dan penjualan, 2) fungsi fisik yang meliputi penyimpanan, pengangukutan dan pengolahan, dan 3) fungsi fasilitas yang meliputi standarisasi dan grading, penaggungan resiko, pembiayaan, dan informasi pasar.

\section{c. Analisis Efisiensi Pemasaran}

Efisiensi pemasaran dapat dilihat dari hasil analisis saluran pemasaran berupa perbandingan total marjin dari setiap saluran pemasaran serta nilai farmer share. Efisiensi pemasaran dapat dilihat dari sebaran marjin dan ratio keuntungan atas biaya. Dengan rendahnya marjin total suatu saluran pemasaran maka saluran tersebut semakin efisien. Marjin pemasaran merupakan selisih harga antara produsen dan konsumen (Hammond, 1977). Formulasi perhitungan komponen penentu efisiensi pemasaran adalah sebagai berikut: (Tomeck dan Robinson, 1990 dalam Sudiyono, 2001)

\section{Saluran Pemasaran}

\section{HASIL DAN PEMBAHASAN}

Berdasarkan hasil wawancara dengan responden awal (petani), pemasaran cengkeh di kecamatan Lhoknga melibatkan beberapa lembaga pemasaran dan ditemukan beberapa pola pemasaran. Lembaga pemasaran yang terlibat yaitu petani, pedagang pengumpul desa, pedagang pengumpul kecamatan, dan pedagang pengumpul kota. Harga yang diterima petani berbeda-beda disetiap saluran 
pemasaran, harga yang diterima berkisar antara Rp. 88.000 sampai dengan Rp. 92.000. pola pemasaran yang terbentuk di Kecamatan Lhoknga adalah sebagai berikut:

1. Saluran I : Petani-Pedagang Pengumpul Desa-Pedagang Pengumpul Kota - Konsumen (Suplier)

2. Saluran II : Petani - Pedagang Pengumpul Kecamatan - Konsumen (Suplier)

3. Saluran III : Petani-Pedagang Pengumpul Kota - Konsumen (Suplier)

Dalam proses pemasaran cengkeh petani tidak memiliki tujuan pemasaran yang tetap, petani cenderung mencari pasar yang menguntungkan berdasarkan harga yang diterima. saluran pemasaran I merupakan saluran terpanjang dalam rantai pemasaran cengkeh di Kecamatan Lhoknga. Dalam saluran ini petani menjual cengkeh kepada pedagang pengumpul desa. Pedagang pengumpul desa menampung komoditi lain seperi pinang yang nantinya setelah tertampung akan dipasarkan kepada pedagang pengumpul kota yang berada di Kota Banda Aceh dengan harga beli cengkeh oleh pedagang pengumpul kota 92.000 rupiah per kilogram dan rata-rata cengkeh ditampung oleh pengumpul desa yaitu 2 ton pertahun. Selanjutnya oleh pedagang pengumpul kota cengkeh akan dijual kepada supplier yang ada di Kota Medan.

Saluran pemasaran II merupakan saluran yang terdiri dari petani, pedagang pengumpul kecamatan, dan konsumen (supplier). Petani langsung menjual hasil panennya kepada pengumpul kecamatan dengan harga Rp 90.000. Rata-rata cengkeh yang terkumpul oleh pengumpul kecamatan berkisar antara 700 sampai 1000 kilogram perminggu. Selanjutnya cengkeh tersebut akan dijual kepada supplier yang berada di Kota Medan dengan harga yang diterima Rp 95.000.

Pada saluran pemasaran III lembaga pemasaran yang terlibat yaitu petani, pedagang pengumpul kota, dan supplier. Petani yang memilih menjual ke pedagang pengumpul kota dikarenakan cengkeh yang dipasarkan relatif banyak, harga yang ditawarkan bisa lebih tinggi dan memiliki transportasi angkut pribadi. Harga yang diterima petani ketika menjual ke pedagang pengumpul kota adalah Rp 92.000 per kilogram. Rata-rata cengkeh yang ditampung per minggu mencapai 1 ton lebih. Selanjutnya cengkeh yang sudah tertampung selama satu minggu akan dijual ke supplier yang berada di Kota Medan dengan harga Rp 95.000.

\section{Fungsi Pemasaran}

Fungsi pemasaran merupakan suatu kegiatan ataupun tindakan yang dapat memperlancar dalam proses penyampaian barang atau jasa dari tingkat produsen ke tingkat konsumen (Limbong, 1987). Berikut fungsi pemasaran yang ada di dalam sistem pemasaran cengkeh di Kecamatan Lhoknga:

Tabel 1. Fungsi Pemasaran Pada Petani dan Lembaga Pemasaran

\begin{tabular}{|c|c|c|c|}
\hline Objek Penelitian & $\begin{array}{c}\text { Fungsi } \\
\text { Pertukaran }\end{array}$ & Fungsi Fisik & Fungsi Fasilitas \\
\hline Petani & Penjualan & $\begin{array}{l}\text { Pengangkutan } \\
\text { Penyimpanan } \\
\text { Pengolahan }\end{array}$ & Informasi Pasar \\
\hline $\begin{array}{c}\text { Pedagang } \\
\text { Pengumpul Desa }\end{array}$ & $\begin{array}{l}\text { Pembelian } \\
\text { Penjualan } \\
\text { Pembelian } \\
\text { Penjualan }\end{array}$ & $\begin{array}{l}\text { Pengangkutan } \\
\text { Penyimpanan } \\
\text { Pengangkutan } \\
\text { Penyimpanan }\end{array}$ & $\begin{array}{l}\text { Informasi Pasar } \\
\text { Informasi Pasar }\end{array}$ \\
\hline
\end{tabular}

Analisis Sistem Pemasaran Cengkeh (Syzygium Aromaticum) Di Kecamatan Lhoknga 


\begin{tabular}{|c|c|c|c|}
\hline Objek Penelitian & $\begin{array}{c}\text { Fungsi } \\
\text { Pertukaran }\end{array}$ & Fungsi Fisik & Fungsi Fasilitas \\
\hline $\begin{array}{l}\text { Pedagang } \\
\text { Pengumpul } \\
\text { Kecamatan }\end{array}$ & & Penyortiran & $\begin{array}{c}\text { Kontrak Jaminan } \\
\text { Harga }\end{array}$ \\
\hline $\begin{array}{c}\text { Pedagang } \\
\text { Pengumpul Kota }\end{array}$ & $\begin{array}{l}\text { Pembelian } \\
\text { Penjualan }\end{array}$ & $\begin{array}{l}\text { Pengangkutan } \\
\text { Penyimpanan } \\
\text { Penyortiran }\end{array}$ & $\begin{array}{c}\text { Informasi Pasar } \\
\text { Kontrak Jaminan } \\
\text { Harga }\end{array}$ \\
\hline
\end{tabular}

Sumber: Data Primer Diolah (2018)

Marjin Pemasaran

Analisis marjin pemasaran dilakukan untuk mengetahui efiensinya sistem pemasaran suatu produk dalam hal ini cengkeh. Marjin pemasaran merupakan selisih dari harga beli dan harga jual setiap lembaga pemasaran yang akan menghasilkan marjin total dari penjumlahan selisih tersebut atau dengan kata lain selisih anatara harga ditingkat produsen dengan harga ditingkat konsumen (Hanafiah dan Saefuddin, 1986)

Berdasarkan hasil yang diperoleh menunjukkan bahwa saluran pemasaran I yang melibatkan petani, pedagang pengumpul desa, pedagang pengumpul kota, dan konsumen (supplier) memiliki marjin total pemasaran sebesar Rp. 7000 per kg, dimana harga jual petani yaitu Rp. 88.000 dan harga beli oleh konsumen (supplier) yaitu Rp. 95.000. Pada saluran II yang melibatkan petani, pedagang pengumpul kecamatan, dan konsumen (supplier) menghasilkan marjin total sebesar Rp. 5000, dimana harga jual petani adalah Rp. 90.000 dan harga beli oleh konsumen (supplier) adalah Rp. 95.000. pada saluran III yang melibatkan petani, pedagang pengumpul kota, dan konsumen (supplier) menghasilkan marjin total sebesar Rp. 3000, dimana harga jual petani adalah Rp. 92.000 dan harga beli oleh konsumen (supplier) adalah Rp. 95.000. Dari uraian tersebut terlihat bahwa saluran yang paling efisien dengan tingkat marjin terendah secara berturut turut adalah saluran III, saluran II, dan saluran I. Namun secara umum keluruh saluran yang ada dapat dikatakan efisien.

\section{Bagian Diterima Petani (Farmer Share)}

Bagian yang diterima petani (farmer share) merupakan persentase selisih harga yang diterima petani dengan harga yang dibayarkan oleh konsumen akhir. Farmer share salah satu dari alat analisis yang dijadikan indikator penilaian tingkat efisiensi suatu sistem pemasaran (Tomeck dan Robinson, 1990 dalam Sudiyono, 2001)

Tabel 2. Bagian Diterima Petani (Farmer Share) Pada Setiap Saluran Pemasaran

\begin{tabular}{lcccc}
\hline $\begin{array}{c}\text { Saluran } \\
\text { Pemasaran }\end{array}$ & $\begin{array}{c}\text { Harga di } \\
\text { Tingkat } \\
\text { Petani } \\
(\mathbf{R p} / \mathbf{K g})\end{array}$ & $\begin{array}{c}\text { Harga di } \\
\text { Tingkat } \\
\text { Supplier } \\
\text { (Rp/Kg) }\end{array}$ & $\begin{array}{c}\text { Marjin } \\
\text { Pemasaran } \\
(\mathbf{R p} / \mathbf{K g})\end{array}$ & $\begin{array}{c}\text { Farmer } \\
\text { Share } \\
(\%)\end{array}$ \\
\hline Saluran I & 88000 & 95000 & 7000 & 92,63 \\
saluran II & 90000 & 95000 & 5000 & 94,73 \\
Saluran III & 92000 & 95000 & 3000 & 96,84 \\
\hline
\end{tabular}

Sumber: Data Primer Diolah (2018)

Nilai farmer share berbanding terbalik dengan marjin pemasaran dimana jika marjin pemasaran semakin tinggi maka ada indikasi tidak efisiennnya suatu sistem pemasaran maka nilai farmer share justru sebaliknya, jika nilai farmer share

Analisis Sistem Pemasaran Cengkeh (Syzygium Aromaticum) Di Kecamatan Lhoknga 
semakin tinggi maka semakin efisien suatu sistem pemasaran. Dari tabel diatas diketahui bahwa saluran pemasaran yang paling efisien berdasarkan nilai farmer share adalah saluran III yaitu sebesar 96,84 persen. Sedangkan nilai farmer share terendah yaitu pada saluran I yakni sebesar 92,63 persen.

\section{Keuntungan Atas Biaya}

Analisis ini bertujuan untuk melihat tingkat kemerataaan dari sebaran biaya maupun keuntungan oleh setiap lembaga pemasaran. Merata atau tidaknya perolehan keuntungan atas biaya dapat dilihat pada nilai $\Pi / \mathrm{Ci}$. Lebih jelas dapat dilihat pada tabel berikut:

Tabel 3. Keuntungan Atas Biaya Pada Setiap Saluran Pemasaran

\begin{tabular}{|c|c|c|c|}
\hline \multirow{2}{*}{ Lembaga Pemasaran } & \multicolumn{3}{|c|}{ Saluran Pemasaran } \\
\hline & 1 & 2 & 3 \\
\hline \multicolumn{4}{|l|}{ Pengumpul Desa } \\
\hline$\Pi$ & 2359 & & \\
\hline $\mathrm{Ci}$ & 1641 & & \\
\hline Rasio $\prod / C i$ & 1,44 & & \\
\hline \multicolumn{4}{|l|}{ Pengumpul Kecamatan } \\
\hline$\prod$ & & 3260 & \\
\hline $\mathrm{Ci}$ & & 1740 & \\
\hline Rasio $\prod / C i$ & & 1,87 & \\
\hline \multicolumn{4}{|l|}{ Pengumpul Kota } \\
\hline$\Pi$ & 1600 & & 1600 \\
\hline $\mathrm{Ci}$ & 1400 & & 1400 \\
\hline Rasio $\prod / C i$ & 1,14 & & 1,14 \\
\hline \multicolumn{4}{|l|}{ Total } \\
\hline$\prod$ & 3959 & 3260 & 1600 \\
\hline $\mathrm{Ci}$ & 3041 & 1740 & 1400 \\
\hline Rasio $\prod / \mathbf{C i}$ & 1,30 & 1,87 & 1,14 \\
\hline
\end{tabular}

Sumber: Data Primer Diolah (2018)

Dari hasil tabel tersebut terlihat bahwa dalam kegiatan pemasaran cengkeh ini tidak ada lembaga pemasaran yang menanggung kerugian. Sebaran biaya dan keuntungan juga terlihat telah merata.

\section{Kesimpulan}

\section{KESIMPULAN DAN SARAN}

1. Fungsi pemasaran yang dilakukan oleh petani meliputi fungsi pertukaran berupa kegiatan penjualan. fungsi fisik berupa pengolahan (penjemuran), penyimpanan dan pengangkutan. Fungsi fasilitas berupa perolehan informasi pasar. Fungsi pemasaran yang dilakukan oleh lembaga pemasaran relatif sama yaitu fungsi pertukaran berupa pembelian dan penjualan. Fungsi fisik berupa penyortiran, penjemuran, penyimpanan, dan pengangkutan. Fungsi fasilitas yaitu jaminan harga dengan perjanjian tertentu, dan informasi pasar.

2. Marjin pemasaran pada saluran pemasaran I yang melibatkan petani, pedagang pengumpul desa, pedagang pengumpul kota, dan konsumen (supplier) memiliki 
marjin total pemasaran sebesar Rp. 7000 per kg. Pada saluran II yang melibatkan petani, pedagang pengumpul kecamatan, dan konsumen (supplier) menghasilkan marjin total sebesar Rp. 5000. pada saluran III yang melibatkan petani, pedagang pengumpul kota, dan konsumen (supplier) menghasilkan marjin total sebesar Rp. 3000.

3. Berdasarkan hasil analisis marjin pemasaran dan nilai farmer share maka dikatahui saluran pemasaran yang paling efisien secara berturut-turut yaitu saluran III dengan marjin sebesar Rp. 3000 dan nilai farmer share 96,84 persen. Saluran II dengan marjin sebesar Rp. 5000 dan nilai farmer share 94,73 persen. Saluran I dengan marjin Rp. 7000 dan nilai farmer share 92,63 persen.

\section{Saran}

1. Perlu adanya upaya untuk meningkatanan kesejateraan petani melalau difungsikannya kembali Koperasi Unit Desa (KUD) sehingga dalam hal permodalan petani dapat terbantu dan dalam pemasaran cengkeh petani akan terbantu dengan harga jual yang lebih tinggi serta stabil dan juga perolehan informasi pasar yang akan lebih memadai.

2. Diharapkan kepada peneliti selanjutnya untuk meneliti terkait dengan transmisi harga, sehingga permasalahan yang ada dapat teridetifikasi dengan sepenuhnya.

\section{DAFTAR PUSTAKA}

Anindasari. (2009). Analisis Pemasaran Kopra di Desa Lemusa Kecamatan Parigi Selatan Kabupaten Parigi Moutong. Jurnal jurusan Ekonomi Pertanian/Agribisnis Fakultas Pertanian. Universitas Tadulako.

Ditjenbun. (2016). Statistik Perkebunan Indonesia Komoditas Cengkeh. Jakarta: Sekretariat Direktorat Jenderal Perkebunan.

Dahl, D.C dan J.W. Hammond. (1977). Marketing And Price Analysis. The Agricultural Industries. New York: Mc Graw Hill Company.

Hadiwijaya, T. (1986). Cengkeh: Data Dan Petunjuk Ke Arah Swa Sembada. Jakarta: PT. Gunung Agung.

Hanafiah, A.M dan Saefuddin. (1986). Tataniaga Hasil Perikanan. Jakarta: Universitas Indonesia Press.

Kotler, P dan Keller, K.L (2008). Manajemen Pemasaran Edisi 12 Jilid 1. Jakarta: Erlangga.

Limbong, W.H dan Sitorus, P (1987). Pengantar Tataniaga Pertanian, Jurusan Ilmu-Ilmu Sosial Ekonomi Pertanian . Bogor: Institut Pertanian Bogor .

Redaksi Sawit Indonesia. "Sektor Perkebunan Berkontribusi Tumbuhkan Ekonomi Nasional”. 3 Agustus 2018. https://sawitindonesia.com/rubrikasimajalah/kinerja/sektor-perkebunan-berkontribusi-tumbuhkan-ekonominasional.html.

Sudiyono, A. (2001). Pemasaran Pertanian. Malang: Universitas Muhammadiyah Malang.

Wirartha, I. M. (2005). Metodelogi Penelitian Sosial Ekonomi. Yogyakarta: Penerbit ANDI. 